\title{
Explaining Persistent Poverty \\ IN SHARE: \\ Does the Past Play a Role?
}

Platon Tinios, Antigone Lyberaki, Thomas Georgiadis

(c) Mea-Mannheim Research Institute for the Economics of Aging 


\title{
2 Explaining Persistent Poverty in SHARE: Does the Past Play a Role?
}

\author{
Platon Tinios, Antigone Lyberaki and Thomas Georgiadis
}

\subsection{Identifying 50 years of social progress}

Poverty alleviation is certainly the most emblematic of European Union ambitions in the field of social policy - encompassing in a visible and politically salient way the cumulative end effect of many separate interventions in social and economic policy. The question posed in this paper is, therefore: Does the past play a role in the $50+$ poverty we see today?

This investigation will proceed in three steps: First, poverty in the two waves of SHARE will be used as the starting point of the analysis. Poverty alleviation is a key motivation for social policy; in a way poverty in our group of 50+ should portray the accumulation of public policies over the life histories of the persons concerned. Old age protection is the most venerable of the objectives of the Welfare State in Europe; the amelioration of the effects of social and economic shocks so that they have no long term effects is a key objective of social policy. Second, a picture of relative deprivation at age 10 is collated from SHARELIFE information and an idea gleaned of its link with poverty status in later life. Childhood poverty is a key objective of anti-poverty policy and is addressed especially in European social policy statements. At the same time, there is a large and inconclusive literature on the intergenerational transmission of inequality (Champernowne and Cowell, 1998; OECD 2008). The analysis is designed to give the initial conditions of the poverty inequality. Third, an attempt is to approach processes of transition from the initial conditions to the observed old age poverty. Factors influencing this could be due to decisions of the individual, such as education, choice of occupation or family arrangement, patterns of savings; they could be due to unforeseen events or shocks: an illness, family breakup, unemployment, migration; they can finally be due to public interventions in the form of income transfers, both while working and in retirement. Particular attention needs to be paid to key features of the type of social policy of relevance to our cohorts and in operation at the midpoint of our sample's lives: the size of the Welfare State, the emphasis it placed on family, labour and social inclusion and the extent of means testing in operation. Expenditure on pensions and most health care expenditure, directed as they were at the previous cohorts, should be excluded from the picture.

Has globalization led to more poverty? Has the intervention of the Welfare State prevented the emergence of poverty? Have the funds disbursed in the form of social programs bought greater equality, and where? Do our detailed data sup- 
port Sapir's (2005) observation that in some countries social expenditure does worse both in terms of economic efficiency and equity? Our investigation is motivated by these large questions; it is our hope that some light may be shed on them.

\subsection{What is to be explained? Poverty 2004-2007}

In European discussions the concept of poverty, albeit with many reminders of its multidimensional nature, has taken centre stage in the attempt to shift emphasis away from discussing efforts at social policy (e.g. by comparing expenditures) and towards outcomes and effectiveness. In political discourse the risk of poverty stands in as the politically most sensitive indicator, a litmus test of efficacy of the 'European Social Model', as well as a test case of the negative effects of globalization. The use of the concept may also be sanctioned by the observation that many social scientists stress the existence of cycles of deprivation, which reinforce and make permanent the effects of deprivation. The starting point of the analysis thus is the state of poverty as portrayed in the two waves of SHARE.

The issues raised are discussed in two papers (Lyberaki \& Tinios, 2005, 2008), so need not be repeated at length: Comparisons are based on net equivalent household income, while the poverty line is corrected for age effects using information about the relative poverty rates for the 50+ population as they are computed using the Survey of Income and Living Conditions (EU-SILC). (See Christelis et al 2009 on how these variables are defined and how they relate to other features, such as wealth and indebtedness). However, as poverty analysis focuses on the bottom part of the income distribution - on what are by definition extreme observations - it is most likely to be affected by data cleaning, imputations and other technical interventions. The numbers presented in Figure 1, using the imputations from wave 1 and 2 of the SHARE, though generally higher are not unlike what is familiar from other sources such as EU-SILC (Eurostat 2009).

Figure 2.1: $\quad$ Poverty with alternative lines (age-corrected) Wave 1 and Wave 2 


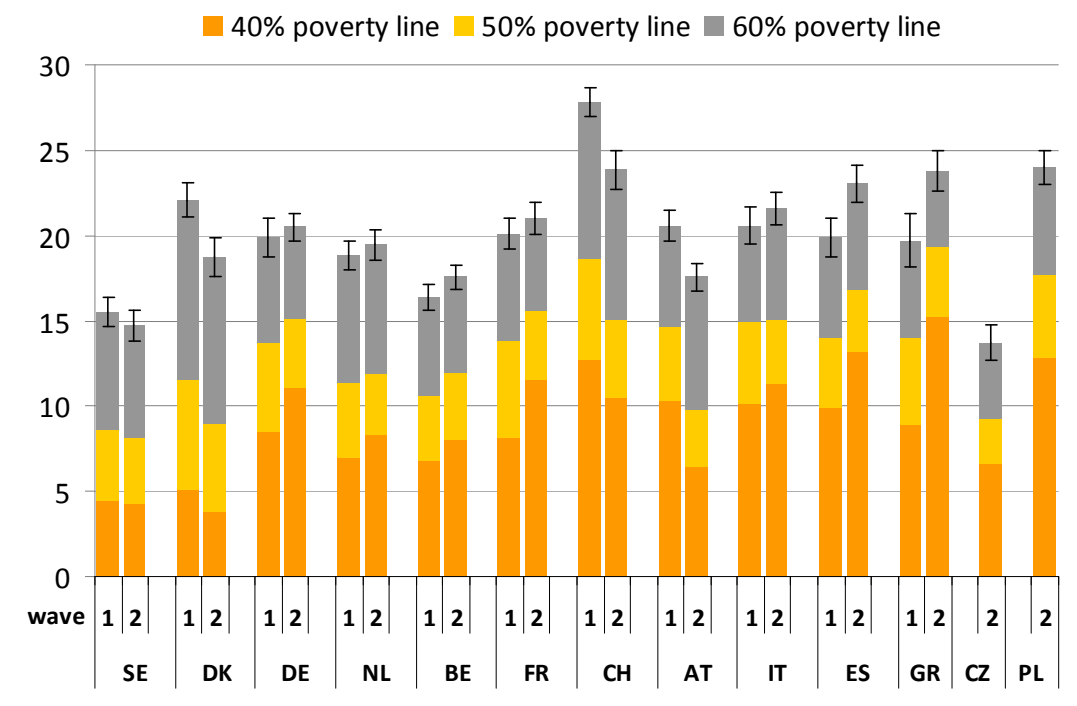

Using information from both previous waves one can construct a new definition of poverty, depending on whether a particular individual in the longitudinal sample is classified under the poverty line in both years, in one year only or in none. This measure of 'persistent poverty' may be interpreted as capturing permanence in poverty (OECD 2008, chapter 6). Alternatively, given that SHARE's wave 1 collected gross income (corrected for taxes and social insurance contributions in the poverty analysis) and wave 2 focused on net income, the analysis may be given an errors-in-variables interpretation as capturing more closely 'true' poverty or the 'hard core' of poverty (the population of the poor is mostly below the income tax threshold, so the gross/net distinction would apply to social insurance only). However it may be, Figure 2 shows that there is considerable movement around the poverty threshold for the longitudinal sample.

Persistent poverty is experienced by between $6 \%$ (SE) and $14 \%$ (GR) of the sample, while a considerably larger proportion (between $21 \%$ in SE and $37 \%$ in ES) runs the risk of being classed as poor at least once in the two waves. In general, the South experiences higher rates of both poverty and persistent poverty, though the differences are far less pronounced than is familiar from other surveys (e.g. the EU's SILC survey -see Eurostat, 2009, Statistics in Focus). In most countries there are more people moving into than moving out of poverty. It is noteworthy that the increase is largest in Spain, where the collapse of housing prices affected imputed housing income for poor owner-occupiers.

Figure 2.2: $\quad$ Poverty and persistent poverty in the longitudinal sample (60\% median poverty line) 


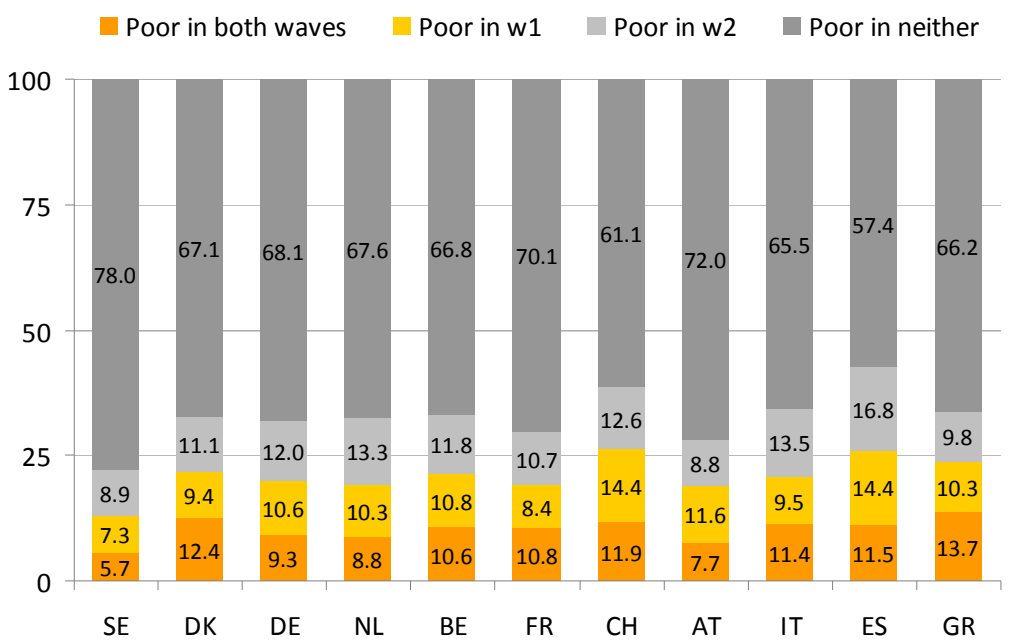

Figure 2.3: $\quad$ Per cent of persistent poor who make ends meet 'with great difficulty'

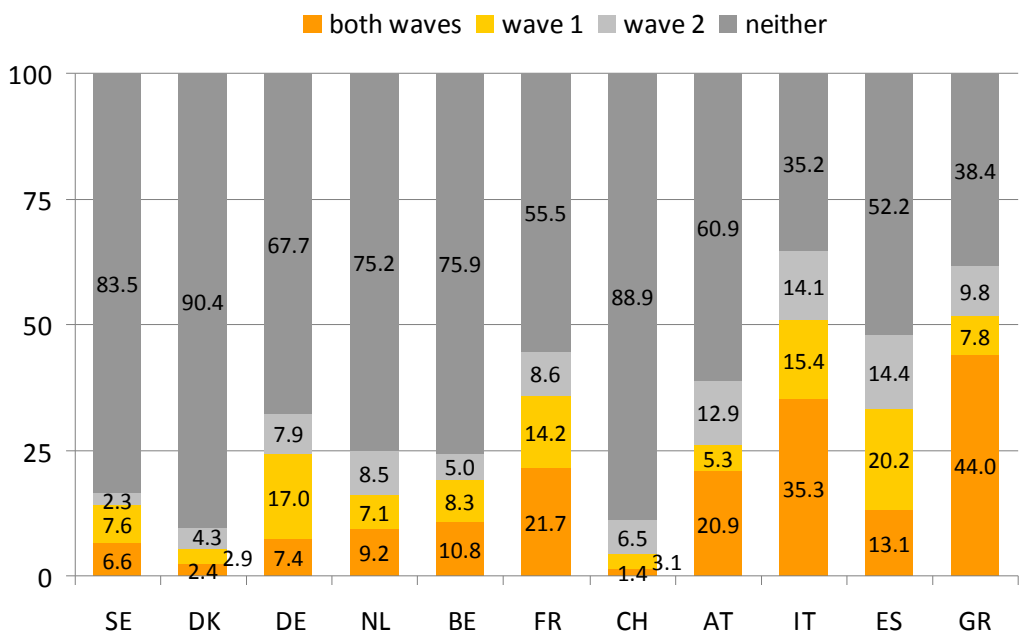

What is the subjective significance of poverty, measured as it is conventionally as a property of the shape of the bottom part of income distribution? A note of caution is sounded by the unexpectedly low percentage of persistent poor who state that they can only make ends meet 'with great difficulty' (Figure 3 ). Thus only $6.6 \%$ of the persistent poor in SE could not make ends meet in both years, while fully $83 \%$ did not mention 'great difficulty' at all. Conversely, the far higher percentages in the South confirm that poverty is, subjectively, more pervasive and less easily bearable phenomenon than in the North. In GR and IT in each year 
$50 \%$ of that year's poor state they make ends meet with difficulty. Such an observation could be explained by greater stoicism in the North, while it could also be due to benefits in kind making the consequences of a risk of income poverty less important and with fewer consequences for the individuals affected.

The 'making ends meet' question as a kind of subjective evaluation of poverty is investigated in detail by Litwin and Sapir (2009) using SHARE wave 1 data. Interestingly, they find that income systematically under-predicts subjective poverty among the very aged, and may even become insignificant for the oldest old. This serves as a reminder that the lived experience of poverty in old age may mean very different things in different countries.

\subsection{Initial conditions: Childhood deprivation in the SHARE sample}

How far is the poverty we now observe among the older population simply the reflection of inherited deprivation? How far is poverty today conditioned by initial conditions during the childhood of our sample?

SHARELIFE has a number of questions on which a picture of deprivation at age 10 can be built up. Eleven events that serve as indicators of childhood deprivation were selected: (i) Fixed bath in accommodation at the age of 10, (ii) Cold running water supply, (iii) Hot running water supply, (iv) Inside toilet, (v) Central heating, (vi) None or very few (0-10 books) in accommodation, (vii) Overcrowded accommodation (three or persons per room), (viii) Experienced financial hardship during childhood, (ix) Experienced hunger during childhood, (x) Poor health status during childhood and (xi) A class of origin indicator (breadwinner of the household working as a farmer or in elementary occupation).

Each of these indicators measures absolute deprivation - in the sense of applying a uniform deprivation criterion across all countries and cohorts. What our analysis requires, however, is an idea of relative deprivation (or its opposite, i.e. relative well-being); an impression thus needs to be built up of how each individual stood as compared to what was the norm around him/her. We have thus used Tsakloglou and Papadopoulos (2001) each person's categorical 'welfare indicator', which is defined as the sum of the deprivation indicators built from the eleven variables above, weighted by the respective country's proportion being not deprived in the specific indicator (details are available by the authors on request). For each country, the estimated childhood relative well-being index takes for each person values between 0 (complete deprivation) and 1 (no deprivation). In other words, a higher value implies less relative childhood deprivation (more wellbeing) for a citizen of a country. In essence, this approach assumes that being deprived during childhood of one event, matters more if that event was more widespread, and hence is more likely to be thought to be part of the 'social norm'. (To ensure adequate degrees of freedom, the analysis was conducted by country, and 
not by cohort, as logic would imply). Assigning a 'deprivation value' to each event depending on its distance from the social norm, has also been employed in other poverty studies (Delhausse, Luttgens and Perelman, 1993).

The results appear in Figure 4. The current persistent poor enjoyed considerably lower relative well-being than those who are not persistently poor. The difference is largest in the Nordic countries and smaller for the South and is always significant except for the Czech Republic.

How closely does childhood deprivation correlate with poverty in 2004-2007? Figures 4 and 5 examine the incidence of poverty among the childhood deprived and vice versa. For the purposes of these analyses (and in the absence of wave 1 data), those 'poor' in wave 2 in PL and CZ are deemed as 'persistent poor'.

Figure 2.4: Childhood Relative Well-being index and current poverty status

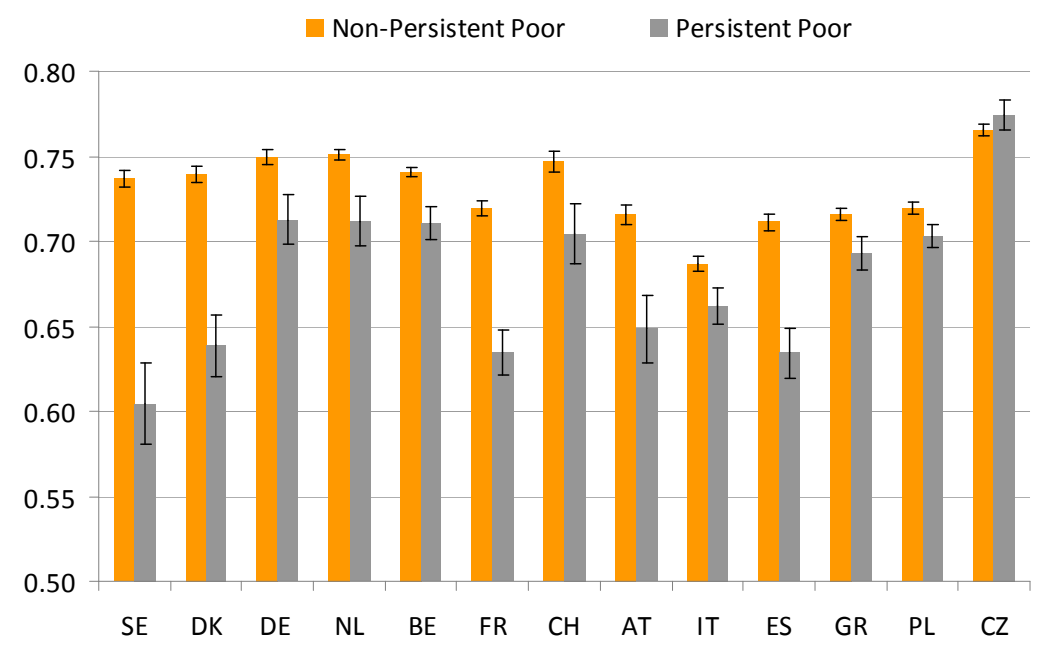

Figure 5 examines the opposite question. How did those who started off with a disadvantage (interpreted as being in the worse-off $20 \%$ in their country) fare in their lives? Being deprived at childhood always translates into greater probability of being poor and/or persistent poor -with the notable exception once more of the Czech Republic.

Figure 2.5: Composition of persistent poverty status, by childhood deprivation status 


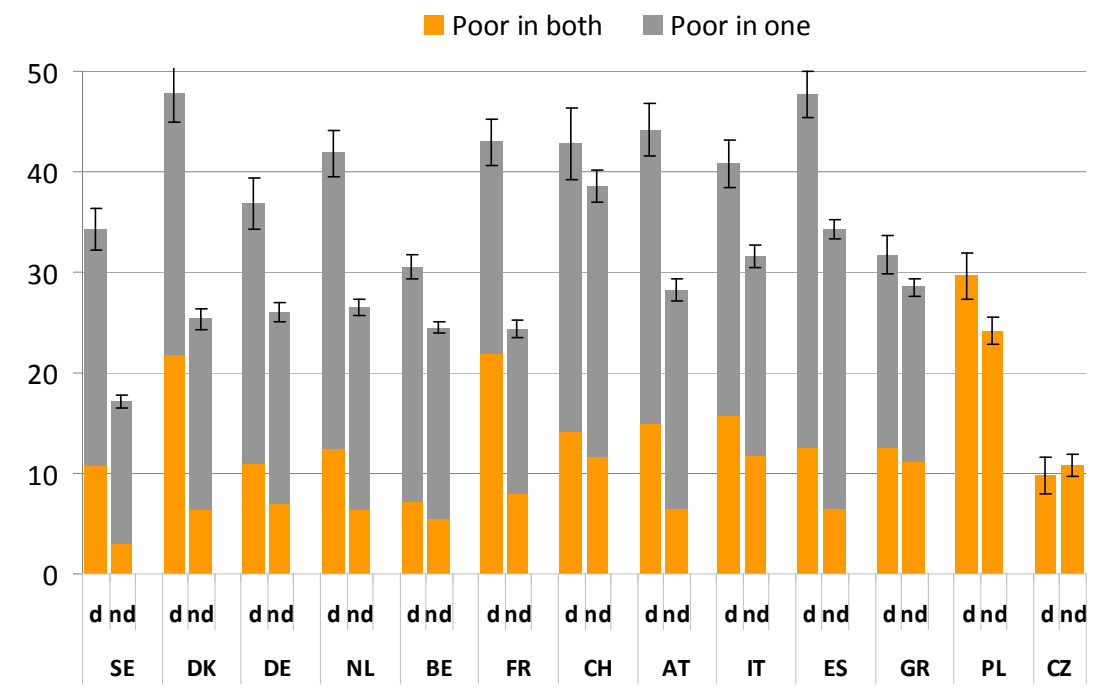

Note: "d" means childhood deprived; "nd" means not deprived in childhood

The impression one gleans from this brief tour of childhood deprivation and contemporary poverty is of a strong link between childhood and later life. The cumulative lack of luck to end at the bottom of the income distribution close to the end of one's life is not automatic, but is subject to variation. These variations may be due to own decisions or to chance accidents. All these effects may be mediated by societal structures, primarily of those of social protection. It is to these factors we now turn.

\subsection{Transitions to poverty - a poverty probit}

Contemporary poverty after age 50 is the cumulative result of decisions and events during the lifetime of the person. Seen in this light it is hardly surprising that no single link or relationship is immediately evident in a preliminary naked-eye analysis. The effects are likely to be complex and will be mediated through other decisions and through social structures which themselves changed over time. This means that (a) a multidimensional analysis is appropriate in picking up marginal effects and (b) if the focus is on social policy a careful model of Welfare State parameters is essential.

This section proceeds to a probit analysis explaining persistent poverty. A probit may be seen as a partial initial response to the first requirement and possibly could provide a start on the second.

The dependent variable is contemporary persistent poverty ( 1 if poor, 0 if not). The explanatory variables are divided into 5 categories: 
1. Demographics: We distinguish three age cohorts 50-65, 65-80 and 80+. Gender, marital status (widow) and foreign-born.

2. Childhood relative well being index in continuous form $(0=$ maximum deprivation).

3. Life time experiences: number of children, Inheritance (>5000 euro), temporary leave of absence for one year or more due to ill-health or disability.

4. Effects of Socio-economic decisions: Never in paid work, Type of paid work (elementary-blue collar, professional-clerk), Education, Retirement history (Employed, retired in past 5 years, in the past 6-20 years, more than 20 ago).

5. Characteristics of the Welfare State in the middle-life (decade of their 40s) of the respondent. Three linked indicators are included, drawing from the ESSPROS dataset: (a) overall size as measured by social protection as \% of GDP, which includes matters such as education only if they are targeted on income (e.g. scholarships to poor pupils), (b) Per cent of total social protection expenditure accounted by family, unemployment, housing and social exclusion function (i.e. not pensions or health) and (c) Per cent of total social protection expenditure accounted for by means-tested benefits. Given that all these variables were subject to different interpretations in transition countries, a transition dummy is also included.

Most of the variables have the expected signs and can provide a plausible account of how initial deprivation may translate to current poverty: The age dummies must be seen in conjunction with the years from retirement variable; being still in employment counteracts a positive effect of being in the younger cohort. Being a widow and being foreign-born exert important influences, as is having had many children or having to have quit a job due to injury. White collar occupations and education predictably play an important role in preventing current poverty.

The childhood well-being index in all cases plays an important and welldefined role, in the sense that its marginal effect appears to depend very little on specification. An interesting observation is that its value alters very little once country dummies and other country specific information is present; this may be taken as evidence that the way original deprivation impinges on current poverty is fairly uniform across countries. If this is so, then it would follow that the type of individual who is most likely to develop from childhood relative to late life poverty is relatively invariant between countries, an important observation in itself.

Turning to the Welfare State characteristics, the emerging picture is very interesting. The proportion of social expenditure spent on matters that affect people of working age (maternity, housing, unemployment) always reduces the probability of being persistent poor in later life, as does the extent of means testing. Welltargeted social expenditure in the mid-life of our respondents continues to pay dividends in later life. The weakly significant positive effect of total expenditure may also have an appealing interpretation: High values for this variable signal large expenditure on old age protection and health. Our respondents at this stage in their lives were mostly working and healthy; for them high pension expenditure 
would be associated with greater taxes rather than higher benefits. We may interpret this effect as a kind of crowding-out of one kind of social welfare by another. The positive sign of this variable is dependent on the presence of a transition country dummy. Excluding transition countries from the estimation reinforces the welfare state effects noted.

Table 2.1: Determinants of Persistent Poverty status: Probit results

\begin{tabular}{|c|c|c|}
\hline Dependent variable $=$ Persistent Poor 2004/2007 & Marginal effect & Std erro \\
\hline \multicolumn{3}{|l|}{ Demographics } \\
\hline Age: $50-64$ years & $0.0645^{* *}$ & 0.0100 \\
\hline Age: $65-80$ years & $\mathrm{F}$ & \\
\hline Age: over 80 years & -0.0143 & 0.0114 \\
\hline Female & -0.0115 & 0.0075 \\
\hline Widowed & $0.0417^{* *}$ & 0.0115 \\
\hline Foreign-born & $0.0613^{* *}$ & 0.0186 \\
\hline \multicolumn{3}{|l|}{ Childhood deprivation index } \\
\hline $\begin{array}{l}\text { Childhood non-deprivation index: for each country } \\
\text { ranges from } 0 \text { (complete deprivation) to } 1 \text { no depriva- } \\
\text { tion }\end{array}$ & $-0.0885^{* *}$ & 0.0234 \\
\hline \multicolumn{3}{|l|}{ Life-time experiences } \\
\hline Number of children & $0.0112^{* *}$ & 0.0022 \\
\hline Received inheritance (>5000 euros) & -0.0031 & 0.0111 \\
\hline $\begin{array}{l}\text { Temporary leave of absence from a job for one year } \\
\text { or more because of ill health / disability }\end{array}$ & $0.0279 *$ & 0.0100 \\
\hline \multicolumn{3}{|l|}{ Socio-economic characteristics } \\
\hline Never in paid work & $\mathrm{F}$ & \\
\hline Paid work: Elementary / Blue-collar & -0.0097 & 0.0112 \\
\hline Paid work: Professional / Clerk & $-0.0372 * *$ & 0.0117 \\
\hline Primary education or lower & $\mathrm{F}$ & \\
\hline Secondary education & $-0.0611^{* *}$ & 0.0079 \\
\hline Higher education & $-0.0731 * *$ & 0.0084 \\
\hline Other employment status & $\mathrm{F}$ & \\
\hline In employment & $-0.0736 * *$ & 0.0074 \\
\hline Retired in past 5 years & $-0.0463 * *$ & 0.0113 \\
\hline Retired in past $6-20$ years & $-0.0578 * *$ & 0.0085 \\
\hline Retired in more than 20 years ago & $-0.0404 * *$ & 0.0091 \\
\hline
\end{tabular}




\begin{tabular}{lrr}
\hline $\begin{array}{l}\text { Social protection expenditure as (\%) of GDP in } \\
\text { middle-life of the respondent }\end{array}$ & $0.0024^{*}$ & 0.0012 \\
$\begin{array}{l}\text { Other social benefits expenditure (except for } \\
\text { pensions and health-related benefits) as (\%) of }\end{array}$ & \\
$\begin{array}{l}\text { social protection expenditure in middle-life of } \\
\text { the respondent }\end{array}$ & $-0.0015^{* *}$ & 0.0006 \\
$\begin{array}{lrr}\text { Means-tested benefits as (\%) of social protection } \\
\text { expenditure in middle-life of the respondent }\end{array}$ & $-0.0029^{* *}$ & 0.0010 \\
$\begin{array}{l}\text { Transition countries (CZ; PL; GDR) } \\
\text { Pseudo R-square }\end{array}$ & $0.1239^{* *}$ & 0.0169 \\
Number of observations & 17478 & \\
\hline
\end{tabular}

Source: SHARE Wave 1, Wave 2 release 2.3.0; Wave 3, release 0

$* *, *$ : Significant at $1 \%, 5 \%$ respectively.

Once country group dummies (roughly corresponding to Esping-Andersen's 1990 groups) are added, the influence of family and other social policies increases, means testing becomes insignificant and total social protection expenditure virtually disappears. Once dummies are included for all countries all Welfare State variables become insignificant, though they retain the original signs.

Thus, welfare policies matter, as does the extent of targeting adopted. However, with minor exceptions, the influence of social policy is benign in a generalized way, affecting the probability of being persistent poor across the board. We have uncovered -at this level of generality at least- little evidence of social policy interacting with specific features of individual lives such as employment or family choices. In particular, the influence of initial conditions is in all cases very strong and it is little altered by adding information on social policy or allowing for specific national effects.

How strong is the social policy effect? To illustrate the answer our probit model gives, at first a baseline high-poverty group was selected and its expected probability of being current persistent poor was computed. Widows, with elementary education, and facing maximum deprivation in childhood, if social policy is at mean levels for the whole sample face a probability of $28.9 \%$. If, however, they lived in a hypothetical country with Germany's targeting and Denmark's family policy, the same group would face a probability of $23.5 \%$, a reduction of 5.4 points or of $18.8 \%$. Conversely, if they were unlucky enough to face Greece's means testing, Italy's family expenditure, and without corresponding reduction in old-age spending (Italy's total expenditure), the predicted probability would rise to $32.2 \%$, a 3.3 points rise or 11.6 relative to the benchmark. The range from the worst social policy case to the best one is from $23.5 \%$ to 32.24 , fully 8.7 percentage points, close to the overall mean. Table 2 shows these and other combinations of social policy stances. 
Table 2.2: $\quad$ The predicted effect of social policy in the probit model, relative to a deprived benchmark

\begin{tabular}{lcc}
\hline $\begin{array}{l}\text { Predicted persistent Poverty Risk Across Social Policy } \\
\text { Models }\end{array}$ & $\begin{array}{r}\text { Predicted } \\
\text { persistent } \\
\text { poverty risk }\end{array}$ & $\begin{array}{r}\text { Relative change } \\
\text { (\%) vis-à-vis the } \\
\text { benchmark }\end{array}$ \\
\hline $\begin{array}{l}\text { Benchmark: Deprived individual + At the means of } \\
\text { social policy parameters (SHARE countries) }\end{array}$ & 28.90 & \\
$\begin{array}{l}\text { Germany's means tested social policy; Denmark's } \\
\text { non-pensions and health-related social policy }\end{array}$ & 23.47 & $-18.8 \%$ \\
$\begin{array}{l}\text { Average means tests Denmark's family social policy } \\
\text { Germany's means tests; Average family social policy }\end{array}$ & 24.66 & $-14.7 \%$ \\
Greece's means tests; Italy's family social policy & 31.91 & $-4.5 \%$ \\
$\begin{array}{l}\text { Greece's means tests; Italy's family social policy; } \\
\text { Italy's total social expenditure }\end{array}$ & 32.24 & $10.4 \%$ \\
\hline $\begin{array}{l}\text { Notes: Baseline population group (Widowed, with elementary education, non-professional } \\
\text { occupation, relative deprived in childhood). }\end{array}$ & &
\end{tabular}

The effect of original deprivation was gauged relative to the same benchmark by simulating the effect of moving the deprivation index from its minimum (in the baseline) to the median value of the deprivation index for all countries. The baseline probability drops drastically from $28.9 \%$ to $21.4 \%$, a reduction of 7.5 points, a little less than the range due to social policy.

\subsection{Conclusion: A 'European Social Model'?}

The results of this paper appear to affirm that 'social policy pays'. Not only contemporaneously as a palliative of immediate problems, but also as a long-term investment. Our results indicate that, once original deprivation is taken into account, targeted public expenditure on family, housing, labour and social exclusion continues to pay dividends decades later - when the beneficiaries have reached retirement age and onwards.

This paper began by asking a number of questions about the effects and efficacy of social policy. Those who think of Social expenditure as 'a factor of production', may find some corroboration for their position; the reach and effectiveness of this factor, though, was by no means uniform. The search for the European social model can go on. 


\section{References}

Champernowne, D.G. and F.A.Cowell. 1998. Economic Inequality and income distribution, Cambridge.

Christelis, D., T. Japelli, O.Paccagnella and G.Weber, 2009, Income, Wealth and Financial Fragility in Europe. Journal of European Social Policy, Vol. 19, pp. 359-376.

Delhausse, B., A. Luttgens, S. and Perelman. 1993. "Comparing measures of poverty and relative deprivation: An example from Belgium". Journal of Population Economics, Vol. 6, pp. 83-102.

Esping-Andersen, G. 1990. The Three Worlds of Welfare Capitalism. Cambridge, Polity press.

Eurostat, 2009. Statistics in Focus, number 46, '79 million EU citizens were at risk-of-poverty in 2007 of whom 32 million were also materially deprived", Luxembourg.

Litwin, H. and E. Sapir. 2009. Perceived Income Adequacy Among Older Adults in 12 Countries: Findings from the Survey of Health, Ageing, and Retirement in Europe. The Gerontologist, Vol. 49, pp. 397-406.

Lyberaki, A and Pl. Tinios. 2005. Poverty and Social Exclusion: a new approach to an old issue. In: A. Börsch-Supan, A. Brugiavini, H. Jürges, J.Mackenbach, J.Siegrist and G. Weber, Health Ageing and Retirement in Europe: First Results from the Survey of Health, Ageing and Retirement in Europe, Mannheim: pp. 302-309.

Lyberaki, A and Pl. Tinios. 2008. Poverty and Persistent Poverty: Adding Dynamics to Familiar Findings. In: A. Börsch-Supan, A. Brugiavini, H. Jürges, A. Kaptein, J.Mackenbach, J.Siegrist and G. Weber, Health Ageing and Retirement in Europe (2004-2007): Starting the Longitudinal Dimension, Mannheim: pp. 276-283.

OECD. 2008. Growing Unequal? Income Distribution and Poverty in OECD countries, Paris.

Sapir, A. 2005. Globalisation and the Reform of European Social Models, Bruegel Policy Contribution.

Tsakloglou, P. and F. Papadopoulos. 2001. Indicators of Social Exclusion in EUROMOD, EUROMOD, Working Paper No. EM8/01. 